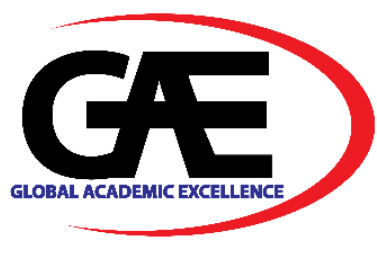

www.ijscol.com

\title{
DRIVER DISTRACTION MEASUREMENT IN REAL ROAD TRAFFIC ENVIRONMENTS: AN INSTRUMENTED VEHICLE STUDY
}

\author{
Mohd Firdaus Mohd Siam ${ }^{1 *}$, Mohd Hafzi Md Isa ${ }^{2}$, Abdullah Sukardi ${ }^{3}$ Azhar Hamzah ${ }^{4}$ Ahmad \\ Khushairy Makhtar ${ }^{5}$ \\ 1 Road User Behavioural Change Research Centre, Malaysian Institute of Road Safety Research (MIROS), Malaysia \\ Email: mfirdaus@miros.gov.my \\ 2 Research Management \& Commercialization Unit, Malaysian Institute of Road Safety Research (MIROS), \\ Malaysia \\ Email: mohdhafzi@miros.gov.my \\ 3 Road User Behavioural Change Research Centre, Malaysian Institute of Road Safety Research (MIROS), Malaysia \\ Email: abdullah@miros.gov.my \\ 4 Road User Behavioural Change Research Centre, Malaysian Institute of Road Safety Research (MIROS), Malaysia \\ Email: azhar@miros.gov.my \\ 5 Faculty of Mechanical Engineering, Universiti Teknologi MARA, Malaysia \\ Email: ahmadkhushairy@uitm.edu.my \\ Corresponding Author
}

\section{Article Info:}

\section{Article history:}

Received date: 14.09 .2020

Revised date: 25.10 .2020

Accepted date: 04.11.2020

Published date: 01.12.2020

\section{To cite this document:}

Siam, M. F. M., Md Isa, M. H., Sukardi, A. Hamzah, A., \& Makhtar, A. K. (2020). Driver Distraction Measurement in Real Road Traffic Environments: An Instrumented Vehicle Study. International Journal of Supply Chain, Operation Management and Logistics, 1 (2), 0111 .

DOI: $10.35631 /$ IJSCOL.12001

\begin{abstract}
:
The Malaysian Institute of Road Safety Research (MIROS) has embarked on the development of an instrumented vehicle that purposely to suit various driver behavioural researches. One of the studies was pertaining to driver distraction. The objectives of this study are to measure the driver distraction in terms of participants' response time and hit rate using the instrumented vehicle. Besides, the study was also conducted to determine whether road conditions and secondary tasks are associated with the participants' response time. The results showed that response times generally increased as a function of road segments as well as exposure to secondary tasks. In terms of road segments, longer response times were observed for the more demanding off-ramp and curvy road sections when compared with expressway driving. Furthermore, for the secondary tasks, the participants took a longer duration to respond to the tactile stimulus, particularly for the difficult n-back task.
\end{abstract}

Keywords:

Instrumented Vehicle, Driver Distraction, Road Safety 


\section{Introduction}

The technology involving vehicles, road traffic engineering and environments are swiftly changing. Vehicles and road systems should be designed to be compatible and suitable with the users and not overload them that can lead to a road crash. In Malaysia, 6,284 fatalities were recorded due to road crashes in the year 2018 (Royal Malaysian Police, 2018). This alarming situation not only occurred in Malaysia but also in worldwide that recorded more than one million are killed every year because of road crashes (World Health Organization, 2018). One of the serious issues that relate to road safety is driver distraction.

\section{Literature Review}

Driver distraction can be defined as doing any task other than driving that can distract the driver's attention (Ranney, 1994). Driver distraction can reduce the driver performance when drivers unable to give tolerable attention to the main task during dangerous situation due to involvement in the additional task that can cause to the loss in the ability to drive safely (Young \& Salmon, 2012). According to 100 cars naturalistic driving study, the main reason for inattention in crashes and close to crashes are because of drivers communicating with other passengers and the use of in-vehicle information systems (Dingus et al., 2006). Many studies revealed that driver distraction is one of the major causal factors in at least a quarter of vehicle crash (McEvoy, Stevenson \& Woodward, 2007; Stutts, Reinfurt, Staplin, \& Rodgman, 2001; Wang, Knipling \& Goodman, 1996). These numbers could increase in the future due to the advancement of in-vehicle technology and electronic gadget usage while driving that has a high possibility to distract drivers.

Studies conducted pertaining to driver distraction in Malaysia is still insufficient. A driving simulator study conducted by MIROS to measure the response time of several secondary tasks including texting usage while driving concluded that $97 \%$ difference of texting response time as compared to baseline task (Mohd Firdaus, Mohd Hafzi, Abdullah, Nurulhana \& Wong, 2014). According to another driving simulator study on mobile phone conversation usage conducted by Mohd Firdaus, Ahmad Azad, Nurulhana and Mohd Khairul Alhapiz (2019) revealed that participants responded to lesser stimuli when dealing with more difficult conversation task. Besides, drivers were more distracted when dealing with more demanding tasks of using the mobile phone (i.e. conversation tasks) as compared to baseline. In addition, participants attended the worst in term of stimuli and higher response time in traffic jam scenario as compared to other scenarios. Furthermore, a self-reported survey pertaining mobile phone usage while driving in Klang Valley has shown that $43.4 \%$ of drivers in Klang Valley used their mobile phone while driving, $61.9 \%$ while stopping at red lights and $53.6 \%$ used their mobile phone during traffic jams (Aini \& Sharifah, 2016). There were no specific accident data reported in term of the type of fault related to driver distraction in Malaysia. Nearly related are careless driving, dangerous driving, dangerous turning, dangerous overtaking, driving too close, careless at entrance or exit and negligent signalling that have a total percentage of 74.81\% (Royal Malaysian Police, 2015). Approximately 176.5 million mobile cellular phones subscribed in Malaysia with a ratio of 5.8 mobile cellular phones for each Malaysian in 2015 (Malaysian Communications and Multimedia Commission, 2015). With the advancement of technologies and the aforementioned figures, it is expected that will raise the driver distraction issue in the Malaysian context. 


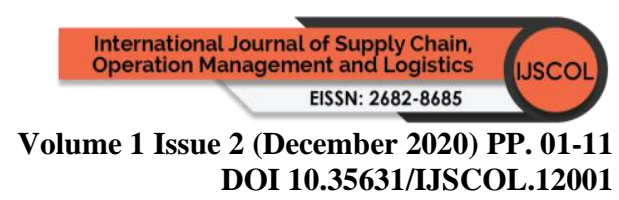

One of the tools to study the driver-related issues specifically for driver distraction is an instrumented vehicle. Data collection that using naturalistic driving approach applying the instrumented vehicle is an optional to the conventional methods whereby self-reports questionnaires, focus group discussion and field observation, etc., which were commonly argued to have limitations in studying driving behaviours (Burns \& Wilde, 1995; Boyce \& Geller, 2001; Dingus, Neale, Klauer, Petersen \& Carroll, 2006). Some of the limitations were the reliability and validity of questionnaires, honesty of respondents, variation in subjectivity level, researcher bias and infrequency of dedicated driving moments. To address these gaps, empirical approaches were used including instrumented vehicles (Ibrahim, 2014).

Looking the critical issues of driver distraction in Malaysia, MIROS conducted the instrumented vehicle study and published the paper that explains the methodology, data analysis and research findings. The study was aimed to measure the driver distraction in term of participants' response time and hit rate for different road conditions and secondary tasks in real road condition.

\section{Materials and Methods}

16 participants ( 8 females, 8 males) took part in the study. Their ages ranged from 25 to 45 years, with a mean of 31.75 years. All participants agreed to take part in the study as volunteers, after reading and signing a consent form detailing the purpose and procedures of the study. They were all licensed drivers and had, on average, driven about 21,300 km a year. The mean of their driving experience is 12.12 years. Participants were selected among MIROS staff.

The MIROS First Instrumented Car (IC01) was used in this study. The platform for the IC01 was a compact car, Perodua Myvi 1.3 litre, sponsored by Perusahaan Otomobil Kedua Sdn. Bhd. (PERODUA). The specifications of the IC01 are shown in Table 1.

Table 1: IC01 Specification According to Car Manufacturer

\begin{tabular}{|l|l|l|}
\hline No & Items & Technical specification \\
\hline 1 & Car Brand / Model & PERODUA Myvi SXi \\
\hline 2 & Engine capacity & 1300 cc (1.3 litres) \\
\hline 3 & Transmission & 5-speed manual \\
\hline 4 & Fuel system & Electronic Fuel Injection (EFI) \\
\hline 5 & Fuel tank capacity (litre) & 40.0 \\
\hline 6 & Tyres & $175 / 65 \mathrm{R} 14$ \\
\hline 7 & Kerb weight $(\mathrm{kg})$ & 945 \\
\hline 8 & Overall length /width / height $(\mathrm{mm})$ & $3750 / 1665 / 1550$ \\
\hline 9 & Interior length / width / height $(\mathrm{mm})$ & $1835 / 1400 / 1270$ \\
\hline 10 & Wheelbase (mm) & 2440 \\
\hline 11 & Colour & White \\
\hline 12 & Body type & 5 door hatchback \\
\hline 13 & Driver position & Right-hand drive (RHD) \\
\hline
\end{tabular}

The instrumented car set-up is categorised into five main components, which are audio and video system, Data Acquisition System (DAQ), power module, DRT device and secondary task device. The components are shown in Figure 1. 


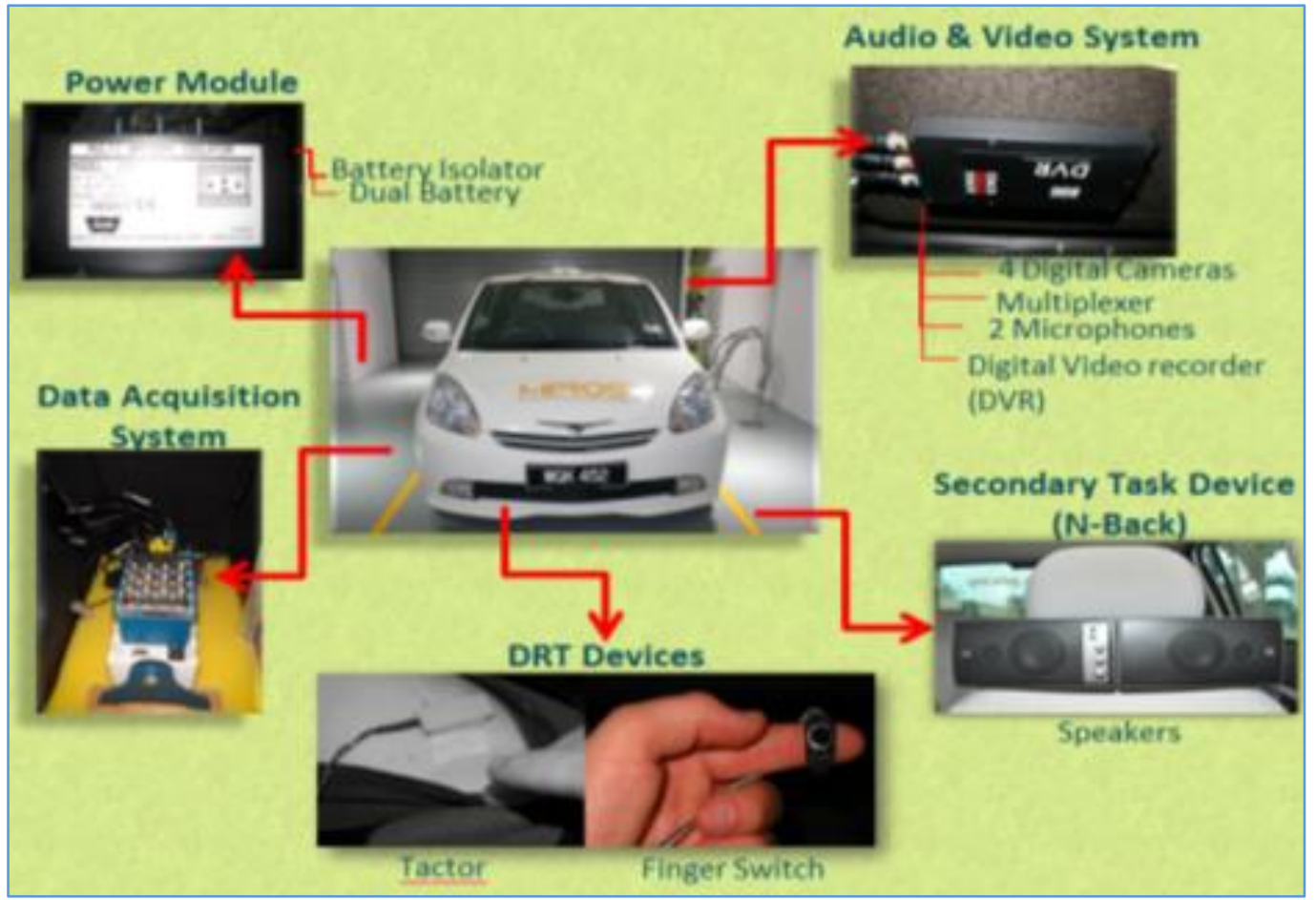

Figure 1: Instrumented Car Set-Up

All runs were video recorded using four digital cameras to provide views of the driver's face, the front and rear driving view as displayed by the instrumented car and a view of the area where the DRT and secondary tasks were carried out. The video screenshot is shown in Figure 2. Two audio inputs were recorded system using a microphone mounted on the driver's seat and driver's visor of the car. Both audio and video are recorded to the Digital Video Recorder (DVR). The multiplexer allows all the four cameras data to be combined into one screen.

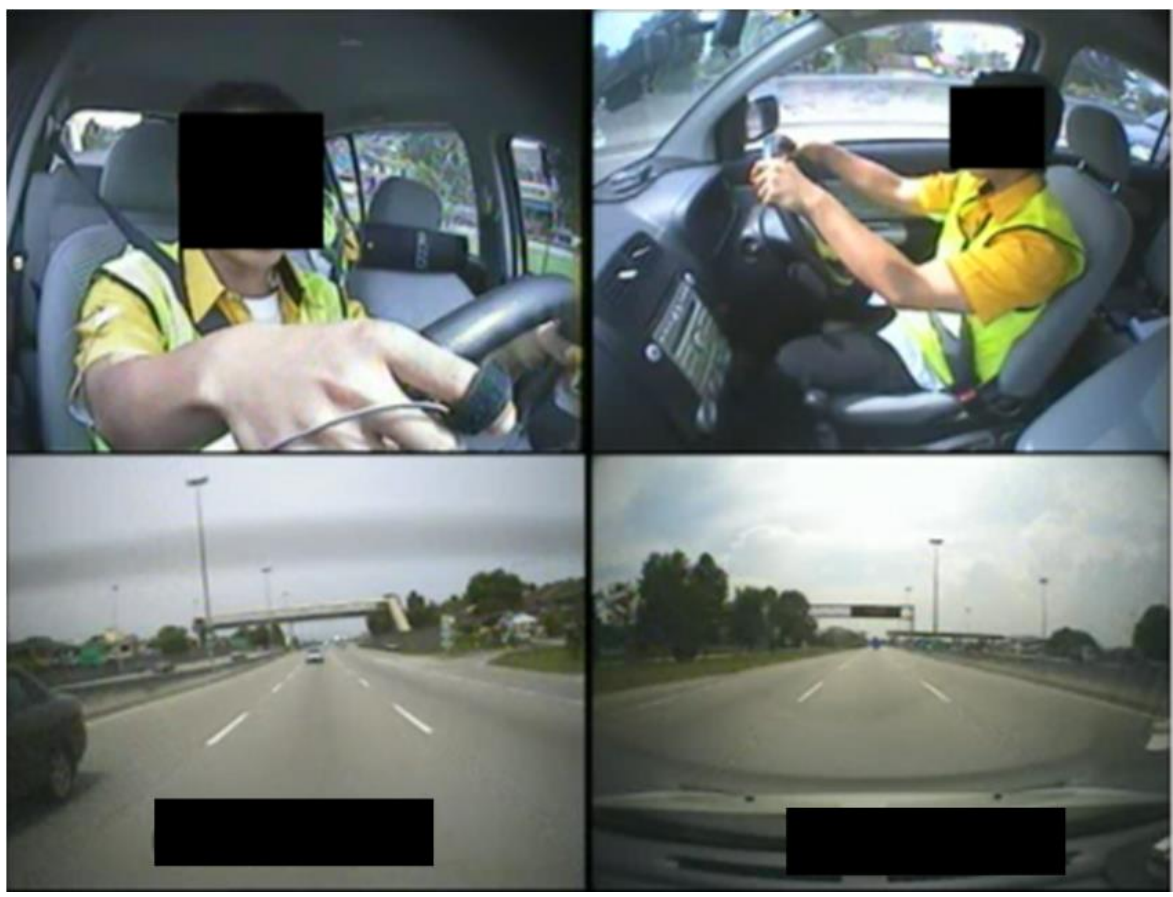

Figure 2: Video Screenshot of The Instrumented Car 


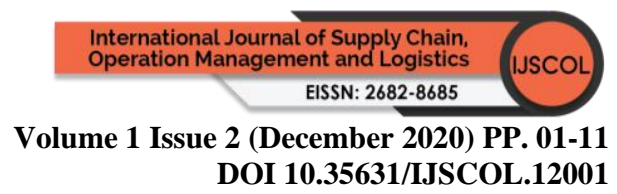

The Data Acquisition System (DAQ) is capable of acquiring the analogue, digital and counter type of signals from the instrumented car system. The signals of the instrumented car that can be acquired are vehicle speed, engine Revolution Per Minute (RPM), horn activation, high beam, left and right blinker, brake, driver seatbelt usage, steering angle and tri-axial accelerometer The function of the power module in the instrumented car is to supply stable electrical power to the DAQ. This is to ensure the reliable operation of the DAQ during the data collection process. The module consists of a battery isolator, which performs as a one-way valve to ensure that the DAQ battery can be recharged without draining the car battery (Azli, Ahmad Azad, Abdullah \& Mohd Firdaus, in press).

Detection Response Task (DRT) is one of the methods for measuring driver distraction (Young, Regan \& Hammer, 2003). The task is purposely for measuring the effects of driving and secondary task demand on driver attention, in particular in the context of driver and vehicle interface evaluation (Engstrom, Larsson \& Larsson, 2013). Tactile DRT were used in the study. The stimuli were presented at temporal intervals randomly and uniformly distributed. The tactile stimulus was presented by using a small electrical vibrator that was placed on the driver's shoulder using medical tape. Participants would respond by pressing a microswitch attached to the right index finger to the steering wheel (van Winsum, Martens \& Herland, 1999).

The Auditory Presentation - Verbal Response Delayed Digit Recall Task (n-back) was used for the secondary task device. It consists of auditory stimuli that the driver listens to and repeats following the specific rules. The task involves aural and memory attention that resembles actual driving activities such as responding to a mobile phone call and conversation with passengers. The mental workload difficulties are simulated using two levels, which are a very easy task demand (0-back) and a moderate level (1-back). A pre-recorded voice was channelled through a set of speaker, acting as the auditory stimuli. The protocols on training and the experimental administration of the auditory presentation were adapted and adopted from the Massachusetts Institute of Technology (MIT) (AgeLab (Mehler, Reimer \& Dusek, 2011). For the 0-back task, the respondents were required to say out loud a number of randomly ordered auditory stimuli (single digits 0 to 9) as it was presented. For the 1-back task, the respondents were required to hold in memory each new number as it was presented and say it out loud with the number 1 position back in the presentation sequence. The experiment for secondary tasks were only conducted along expressway instead of curvy and ramp road segments, as we perceived higher risks for participants to be involved in accidents.

The procedure of the study is summarised and illustrated with the flow chart in Figure 3 . The implementation of the procedure requires approximately one and a half-day (11 hours) to be completed by a participant. 


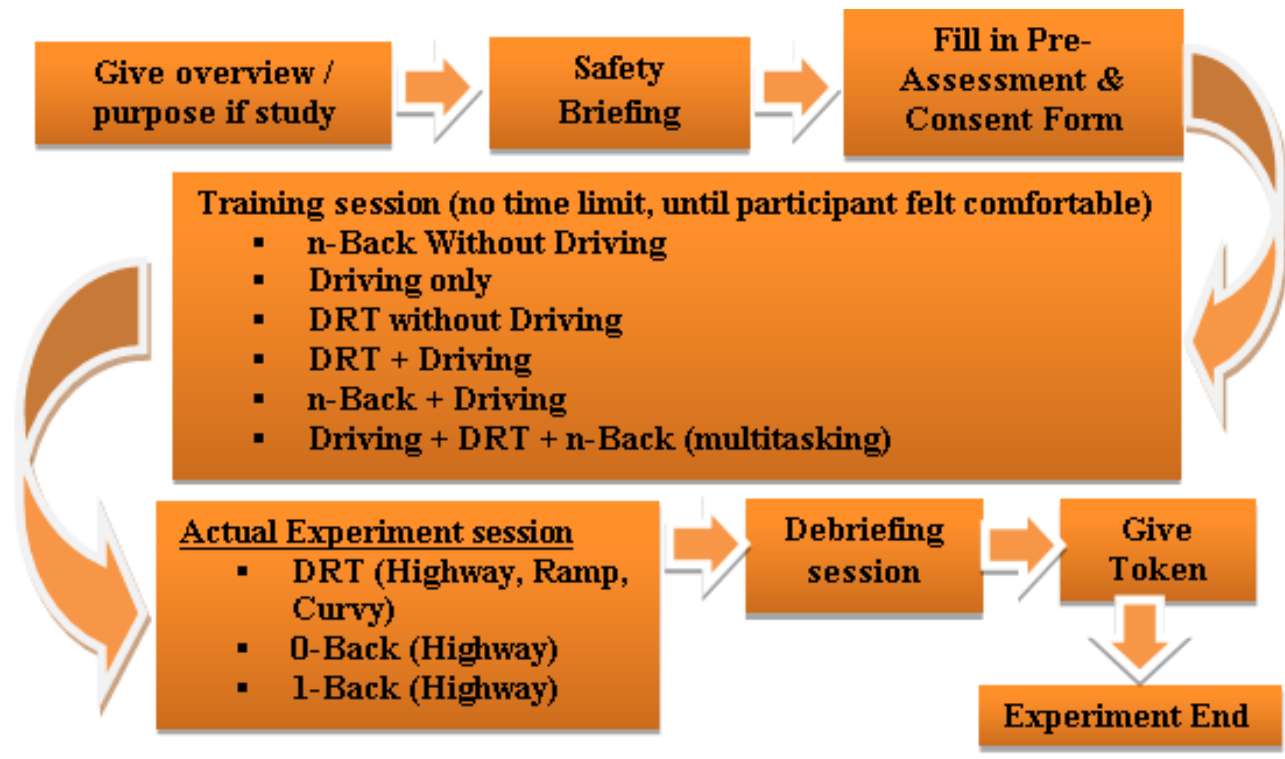

Figure 3: Procedure of The Study

There are some guidelines and instructions that needed to be given to participants before training and executing the actual task. Prior to the detailed briefing, participants were given an overview of the experiment, its expected duration and the experiment procedure. The researcher emphasised that the intention of the experiment was not to test participants' skills. The secondary task to be evaluated and the general principles behind the DRT were explicitly explained by the researcher. The participants were instructed to emphasise on the primary task (i.e. driving) and do their best to perform the DRT and the secondary task under evaluation. It was explained that continuously pressing the button regardless of stimulus presentation will not yield better performance results. The safety briefing was given to the participants before the experiment is conducted. The important safety elements needed to be conveyed are the importance of wearing a safety vest, driving safely, adhering to the legal speed limit and obeying all traffic rules. Prohibition of using mobile phones while driving, emergency response measures and provision of accident compensation was emphasised to the participants. In addition, the pre-assessment forms and informed consent forms were filled out by all participants. There were six sub-sessions for the training session as shown in Figure 3, which are n-back without driving, driving only, DRT without driving, DRT with driving, n-back with driving, and Driving with DRT and n-Back (multitasking). There was no time limit given to each participant. Each training session was stopped when the participants felt comfortable to conduct each of the tasks given. Participants were free to stop the training without any coercion. Between sub-sessions, participants were given time to rest about five to ten minutes.

During the actual experiment session, each participant needs to complete the full task and they were allowed to stop the experiment without any coercion. In each task session, participants were given time to rest about five to ten minutes. The sequence of the task uses the counterbalancing condition that adapts a balanced Latin square as shown in Table 2. 
Table 2: List of Tasks for Each Participant

\begin{tabular}{|c|c|c|c|c|}
\hline Participant no. & \multicolumn{4}{|c|}{ Tasks } \\
\hline 1 & DRT & DRT\&N0 & BL & DRT\&N1 \\
\hline 2 & DRT\&N0 & DRT\&N1 & DRT & $\mathrm{BL}$ \\
\hline 3 & DRT\&N1 & $\mathrm{BL}$ & DRT\&N0 & DRT \\
\hline 4 & $\mathrm{BL}$ & DRT & DRT\&N1 & DRT\&N0 \\
\hline Participant No. & \multicolumn{4}{|c|}{ Tasks } \\
\hline 5 & DRT & DRT\&N0 & $\mathrm{BL}$ & DRT\&N1 \\
\hline 6 & DRT\&N0 & DRT\&N1 & DRT & BL \\
\hline 7 & DRT\&N1 & $\mathrm{BL}$ & DRT\&N0 & DRT \\
\hline 8 & $\mathrm{BL}$ & DRT & DRT\&N1 & DRT\&N0 \\
\hline Participant No. & \multicolumn{4}{|c|}{ Tasks } \\
\hline 9 & DRT & DRT\&N0 & $\mathrm{BL}$ & DRT\&N1 \\
\hline 10 & DRT\&N0 & DRT\&N1 & DRT & BL \\
\hline 11 & DRT\&N1 & $\mathrm{BL}$ & DRT\&N0 & DRT \\
\hline 12 & BL & DRT & DRT\&N1 & DRT\&N0 \\
\hline Participant No. & \multicolumn{4}{|c|}{ Tasks } \\
\hline 13 & DRT & DRT\&N0 & $\mathrm{BL}$ & DRT\&N1 \\
\hline 14 & DRT\&N0 & DRT\&N1 & DRT & BL \\
\hline 15 & DRT\&N1 & $\mathrm{BL}$ & DRT\&N0 & DRT \\
\hline 16 & BL & DRT & DRT\&N1 & DRT\&N0 \\
\hline
\end{tabular}

Notes:

- BL: Driving only (for all road segments - expressway, off-ramp \& curvy)

- DRT: Driving with DRT (for all road segments - expressway, off-ramp \& curvy)

- DRT \& N0: Driving with 0-Back (for expressway only)

- DRT \& N0: Driving with 1-Back (for expressway only)

The experiment was conducted on three different roads which are the expressway, off-ramp and curvy road. The expressway involved along Kajang Silk Highway from Sungai Ramal Toll Plaza to Petronas Petrol Station SKVE (E18, E26). The distance travelled was about $11.5 \mathrm{~km}$ and took about 10 minutes of driving period. For the off-ramp road, it involved the route from a flyover at Petronas Petrol Station SKVE to a flyover after third off-ramp (E26). The distance travelled was about $2.9 \mathrm{~km}$ and took about three minutes of driving period. Whereas for curvy road, it involved the route from Kampung Jenderam Hilir to Bandar Baru Salak Tinggi (B48). The distance travelled was about $11 \mathrm{~km}$ and took about 10 minutes of driving period.

Upon completion of all the experiment tasks, the participants were interviewed on their experience while doing the driving session at the specified room. Then, the participants were thanked and given a token of appreciation for participating in the experiment.

\section{Results and Discussion}

The one-way ANOVA was used to compare the means of three categories of road types (expressway, off-ramp and curvy roads) and secondary tasks (no task, 0-back task and 1-back task). All the statistical analyses were performed using Statistical Package for Social Science (SPSS). 


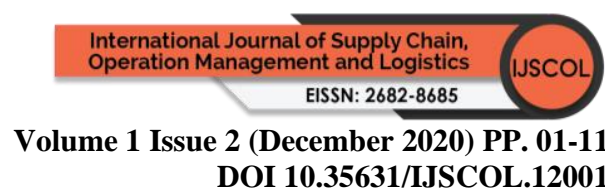

In this study, the two performance measures calculated are hit rate and response time. The definition of hits are the number of stimuli replied to within 200-2500 ms from stimulus inception. The hit rate is defined as the number of hits divided by the total number of stimuli during a task given to the participant. In this study, the hit rates for all tasks exceeded $90 \%$ and there is no significant difference observed between all tasks (road segment and secondary task). This is aligned with the findings obtained from studies conducted by Transport Canada (Harbluk, Burns, Tam \& Glazduri, 2013).

The response time (RT), on the other hand, is defined as the time from stimulus inception until the response from the micro-switch is recorded. Analysis of the data showed that off-ramp recorded the highest mean of RT, followed by curvy road and expressway, as shown in Figure 4. Slightly high standard errors were found for off-ramp and curvy but still within acceptable values. Further analysis using ANOVA technique indicated that at least one pair of mean RT between the road segment categories was significantly different $(F(2,45)=4.94, p=0.011)$. Subsequent post-hoc analysis (LSD procedure) suggests that the mean RT between expressway and off-ramp, and expressway and curvy road were significantly different. On the other hand, the mean RT between off-ramp (310 ms) and curvy road $(297 \mathrm{~ms})$ was not significantly different. This shows that the RTs for off-ramp and curvy road were significantly longer than expressway, which is also supported by Harbluk, Burns, Tam and Glazduri (2013).

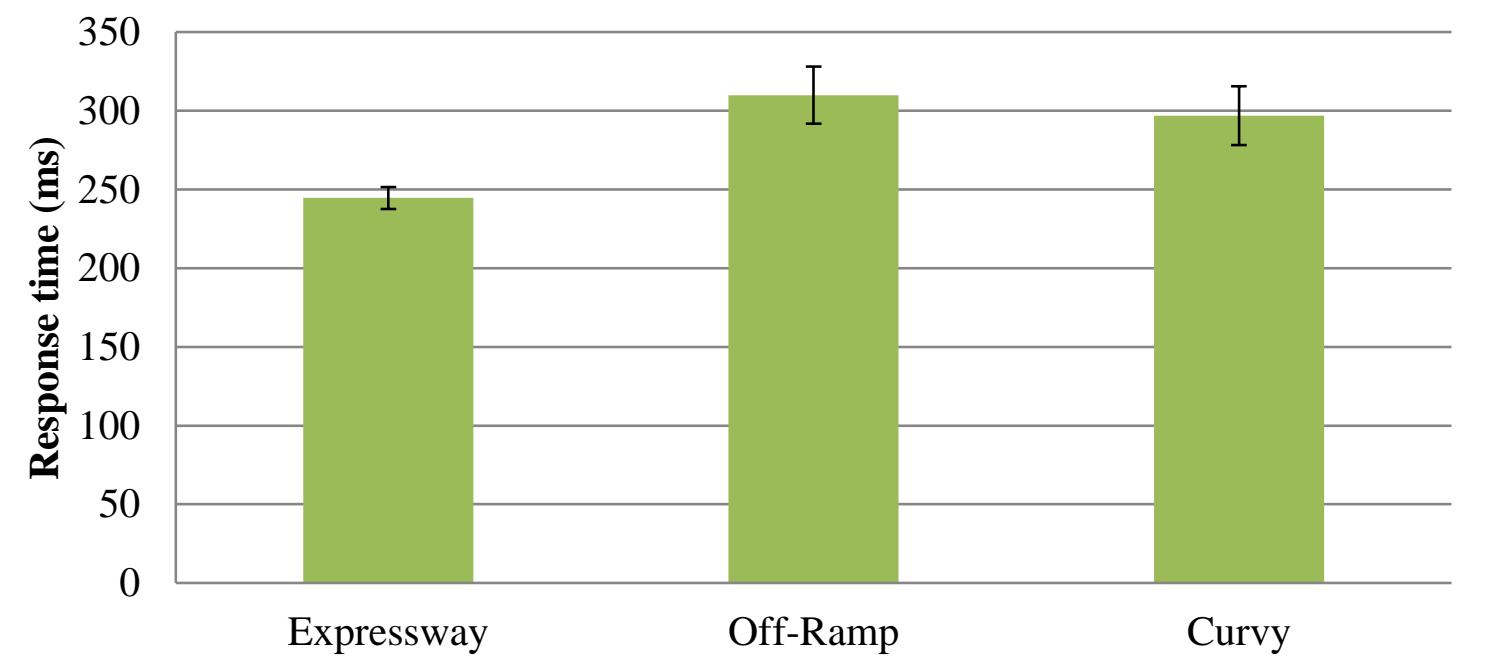

Figure 4: Response Times for Expressway, Off-Ramp and Curvy Road Segments (Mean \pm Standard Error)

The DRT performance for secondary tasks (n-back) was measured as well. Figure 5 shows that RT was longer for the more difficult n-back task (1-Back), followed by the easier version nback task (0-Back) and baseline. Analysis using the ANOVA test revealed that RTs differed significantly across the three tasks $(F(2,45)=14.80, p<0.01)$. Although the standard errors for 0-back and 1-back were slightly higher than the baseline, the values were still within the acceptable range. Further post-hoc comparisons using the LSD procedure indicated that the mean RT for baseline was significantly different than the 0-Back and 1-Back tasks. However, the mean RT for 0-Back task did not significantly differ from the 1-Back task. Overall, longer RTs were observed for the more demanding n-back tasks when compared with baseline driving. 


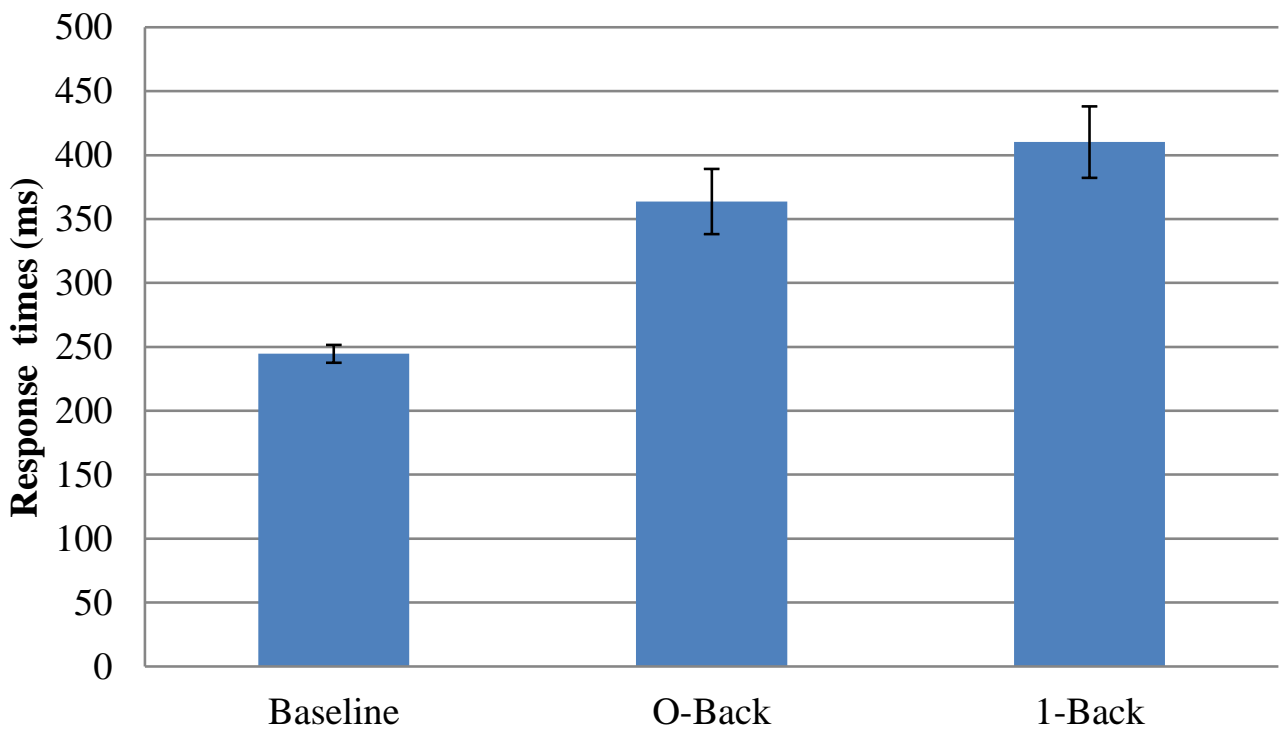

Figure 5: Response Times for With and Without Secondary Task (Mean \pm Standard Error)

\section{Conclusion}

In a nutshell, the objectives of the study were achieved whereby to measure the driver distraction in term of participants' response time for different road conditions and secondary tasks in real road condition using the instrumented vehicle. Overall, the results show that response times generally increased as a function of road manipulation as well as exposure to secondary tasks. The findings of this research indicate that in term of road segments, longer response times were observed for the more demanding off-ramp and curvy road sections when compared with the expressway. Furthermore, for the secondary tasks, the participants took a longer duration to respond to the tactile stimulus, particularly for the difficult n-back task (1back). This study shows that doing the secondary task while driving is considered a distracting activity that possibly raises the risk of a crash. As this study involved on-road experiment, the demonstration of participants performing a secondary task for curvy and off-ramp road segments could not be tested due to safety reasons. The alternative study shall utilise driving simulator i.e., less risk and under a controlled environment to perform the experiment, not only for the n-back tasks but also on other secondary tasks.

\section{Acknowledgement}

The authors would like to express their sincere gratitude to MIROS management, Director of Road User Behavioral Change Research Center (RUBC) and members of Human Reaction Simulation Unit (HURAS) for their valuable commitment and support.

\section{References}

Aini, A.B. \& Sharifah, O. (2016), Using Mobile Phone while Driving as a Contributing Factor to Road Crashes among Motorist in Klang Valley: A Self-Reported Study, MRR No. 201 (2016), Kuala Lumpur: Malaysian Institute of Road Safety Research.

Azli A. Z., Ahmad Azad A. R., Abdullah S. \& Mohd Firdaus M. S. (In press), Instrumented car system enhancement (ICSE) development report, $M C P$, Kuala Lumpur: Malaysian Institute of Road Safety Research. 


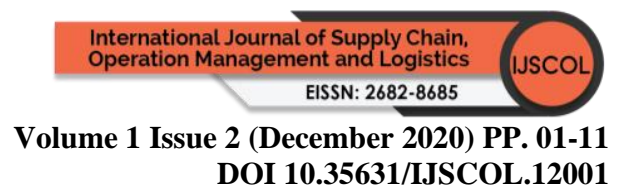

Boyce, T. E., \& Geller, E. S. (2001). A Technology to Measure Multiple Driving Behaviours Without Self-Report Or Participant Reactivity. Journal of Applied Behaviour Analysis, 34(1), 39-55.

Burns, P. C., \& Wilde, G. J. (1995). Risk taking in male taxi drivers: Relationships among personality, observational data and driver records. Personality and Individual Differences, 18(2), 267-278.

Dingus, T. A., Neale, V. L., Klauer, S. G., Petersen, A. D., \& Carroll, R. J. (2006). The development of a naturalistic data collection system to perform critical incident analysis: an investigation of safety and fatigue issues in long-haul trucking. Accident Analysis \& Prevention, 38(6), 1127-1136.

Dingus, T.A, Klauer, S. G., Neale, V. L., Petersen, A., Lee, S. E., Sudweeks, J., Perez, M. A., Hankey, J., Ramsey, D., Gupta, S., Bucher, C., Doerzaph, Z. R., Jermeland, J. \& Knipling, RR (2006), The 100 Car Naturalistic Driving Study Phase 2- Request Of The 100 Car Field Experiment, NHTSA DOT, Report No: HS B10 593.

Engstrom J., Larsson P. \& Larsson C. (2013). Comparison of Static and Driving Simulator Venues for The Tactile Detection Response Task. In: $7^{\text {th }}$ International Driving Symposium on Human Factors in Driver Assessment, Training, and Vehicle Design, Bolton Landing, New York; 17-20 June.

Harbluk, J., L., Burns, P, C., Tam, J. \& Glazduri, V. (2013). Detection Response Tasks: Using Remote, Head-mounted and Tactile Signals to Assess Cognitive Demand While Driving. In: Proceedings of the Seventh International Driving Symposium on Human Factors in Driver Assessment, Training and Vehicle Design, June 17-20, 2013, Bolton Landing, New York. Iowa City, IA: Public Policy Centre, University of Iowa, 2013: 78-84. https://doi.org/10.17077/drivingassessment

Ibrahim, M. K. A. (2014). An instrumented motorcycle assessment of motorcycle rider behaviour: benefits and lessons learnt. In Proceedings of International Crashworthiness Conference (ICRASH 2014).

Malaysian Communications and Multimedia Commission (2015). Communications and Multimedia Pocket Book of Statistics. Cyberjaya, Selangor: MCMC.

McEvoy, S. P., Stevenson, M. R. \& Woodward, M. (2007). The Contribution of Passengers Versus Mobile Phone Use to Motor Vehicle Crashes Resulting in Hospital Attendance by The Driver. Accident Analysis and Prevention, 39, 1170-1176.

Mehler, B., Reimer, B. \& Dusek, J. (2011), MIT AgeLab Delayed Digit Recall Task (n-back) (MIT AgeLab White Paper Number 2011-3B), Cambridge, MA: MIT.

Mohd Firdaus, M. S., Ahmad Azad, A. R., Nurulhana, B. \& Mohd Khairul Alhapiz, I. (2019). Distracted Driving While Doing Mobile Phone Conversation: A Driving Simulator Study. Journal of Advanced Research Design, 1, 1-9.

Mohd Firdaus M. S, Mohd Hafzi M. I., Abdullah S., Nurulhana B. \& Wong, S. V. (2014), Measuring Attention and Performance in Simulated Road Traffic Environments using Detection Response Task Method, MRR No. 150/2014, Kuala Lumpur: Malaysian Institute of Road Safety Research.

Ranney, T. A. (1994). Models of Driving Behaviour: A Review of Their Evolution. Accident Analysis \& Prevention, 26, 733-750.

Royal Malaysian Police (2018). Statistical Report of Road Accident in Malaysia in 2017. Kuala Lumpur: Traffic Branch, Bukit Aman.

Royal Malaysian Police (2015). Statistical Report of Road Accident in Malaysia in 2015. Kuala Lumpur: Traffic Branch, Bukit Aman.

Stutts, J. C., Reinfurt, D. W., Staplin, L. \& Rodgman, E. A. (2001). The Role of Driver Distraction in Traffic Crashes. A Report Prepared for The AAA Foundation for Traffic Safety, Washington, DC. 


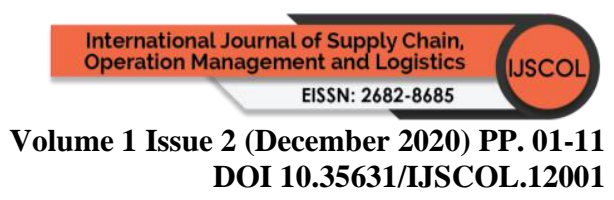

van Winsum, W., Martens, M. \& Herland, L. (1999). The Effects of Speech Versus Tactile Driver Support Messages on Workload, Driver Behaviour and User Acceptance, TNO Report TM-99-C043, Soesterberg: TNO Human Factors Research Institute.

Wang, J.-S., Knipling, R. R. \& Goodman, M. J. (1996). The Role of Driver Inattention in Crashes: New Statistics from the 1995 Crashworthiness Data System. In 40th Annual Proceedings Association for The Advancement of Automotive Medicine (pp. 377-392). Des Plaines, IA: AAAM.

World Health Organization (2018). Global Status Report on Road Safety 2018: Summary. Geneva: (WHO/NMH/NVI/18.20). Licence: CC BY-NC-SA 3.0 IGO).

Young, K, \& Salmon, PM (2012), Examining the Relationship Between Driver Distraction and Driving Errors: A Discussion of Theory, Studies and Methods, Safety Science, 50: 165174.

Young K. L., Regan M. A. \& Hammer M. (2003). Driver Distraction: A Review of the Literature. Report No.206. Victoria: Monash University Accident Research Centre. 